\title{
PRODUCTION OF INCREASED RENAL SODIUM EXCRETION BY \\ THE HYPOTONIC EXPANSION OF EXTRACELLULAR FLUID VOLUME IN RECUMBENT SUBJECTS ${ }^{1}$
}

\author{
By MAURICE B. STRAUSS, ROBERT K. DAVIS, JACK D. ROSENBAUM, AND \\ ELSIE C. ROSSMEISL \\ (From the Medical Service and the Research Laboratory, Cushing Veterans Administration \\ Hospital, Framingham, Mass.)
}

(Submitted for publication August 31, 1951; accepted October 15, 1951)

The renal excretion of sodium is obviously determined by the difference between the amount filtered through the glomeruli and the amount reabsorbed by the tubules. In the isolated, perfused kidney, increasing the filtered sodium chloride either by raising filtration rate or salt concentration in the perfusate increases the excretion of salt, but even in this preparation changes in tubular reabsorption play a significant role (1, 2 ). While there is no reason to doubt that alteration in the filtered load may act in the same direction in the intact animal as in the isolated kidney, changes in tubular reabsorption appear to be of considerable importance in regulating sodium excretion (3), as possibly first suggested by Starling and Verney (1) slightly over a quarter century ago: "Our experiments show that even a concentration of sodium chloride in the blood far greater than normal is unable per se to bring about its elimination. It seems, therefore, that some hormone or hormones arising in the tissues pass by way of the blood stream to the kidney, making it cognizant of the state of the tissues in their content of water and chloride and moderating the reabsorptive mechanism in accordance with the needs of the organism at the time." The evidence that adrenal cortical secretion plays a role in controlling tubular sodium reabsorption need not be recounted here, nor the fact that the anterior pituitary gland exercises a certain degree of control over the adrenal cortex. However, even in the absence of the adrenal cortex, sodium balance can be achieved if the intake is sufficiently large, while in the absence of the anterior pituitary, se-

\footnotetext{
1 Reviewed in the Veterans Administration and published with the approval of the Chief Medical Director. The statements and conclusions published by the authors are the result of their own study and do not necessarily reflect the opinion or policy of the Veterans Administration.
}

rious disturbances. in sodium metabolism rarely occur unless the individual is subjected to stresses beyond the ability of the autonomous regulatory powers of the kidney and possibly of the adrenal cortex to compensate.

Under certain circumstances the rate of sodium excretion can be correlated with the concentration of sodium in the extracellular fluid. Such is not invariably the case. Thus the augmented sodium excretion associated with an increased dietary intake of salt may be related to a rise in serum sodium, but under these circumstances there is a concomitant expansion of extracellular fluid volume. On the other hand in primary water depletion, when serum sodium concentration also rises, but extracellular volume contracts, there is actually diminished urinary excretion of sodium (4), suggesting that the volume of extracellular fluid (or some associated factor) rather than its osmolar concentration is the stimulus to salt retention and excretion (5). Accordingly it seemed of interest to determine whether it was the volume of water in the body as a whole or in some compartment that played a role in controlling sodium excretion.

Welt and Orloff (6) have infused into semirecumbent subjects 50 to $100 \mathrm{gm}$. of salt-poor human albumin in 25 per cent solution, thereby increasing calculated plasma volume by from 22 to 51 per cent in nine experiments. Neither during the period of infusion (one hour for $50 \mathrm{gm}$., two hours for $100 \mathrm{gm}$.) nor during the ensuing two hours was there any increase in the rate of renal excretion of $\mathrm{Na}$ or $\mathrm{Cl}$. Creatinine and urea clearances and the concentrations of sodium and chloride in the serum were unchanged.

They also infused $1,875 \mathrm{ml}$. of 4 per cent albumin in 5 per cent glucose into one normal subject, expanding calculated plasma volume by 31 per cent and causing a small fall in serum sodium 
and chloride concentration. Creatinine clearance, and sodium and chloride excretion were unaltered during the two hours of infusion and in the following two hours, although a striking water diuresis occurred.

In other experiments these same workers were unable to demonstrate that the infusion of $2,280 \mathrm{ml}$. of 4,5 or 6 per cent albumin in normal saline produced any changes in sodium or chloride excretion other than those which occurred during the control infusion of $2,280 \mathrm{ml}$. of normal saline without albumin. Similarly, in subjects whose extracellular volume had been expanded by the infusion of $2,500 \mathrm{ml}$. of normal saline, the subsequent infusion of $200 \mathrm{ml}$. of 25 per cent albumin produced no changes in sodium excretion other than those which occurred with a control infusion of $200 \mathrm{ml}$. of normal saline.

Since Welt's and Orloff's subjects receiving isoor hypo-oncotic albumin solutions were moderately hydropenic by virtue of abstinence from fluids for 10 to 14 hours before, as well as during the experiments, we have repeated the studies with isooncotic albumin in 5 per cent glucose, employing subjects who were undergoing "maximum" water diuresis at the time (see Methods). Under these conditions there occurred a slight transient increase in sodium excretion of the same magnitude as that which followed the administration of an amount of sodium acetyltryptophanate equal to that in the albumin. Since these subjects, whose antidiuretic hormone production presumably had already been suppressed by the water load, exhibited no further increase in diuresis, these observations substantiate the hypothesis of Welt and Orloff that the water diuresis which they observed is the result of inhibition by the expanded plasma volume of the secretion of antidiuretic hormone.

It thus appears that the expansion of plasma volume by the infusion of hypo-, iso-, or hyperoncotic solutions of albumin in normal recumbent subjects is without significant effect on the renal excretion of sodium and chloride.

The effect of increasing the total volume of water in the body on the urinary excretion of sodium is not as clearly defined. Crutchfield and Wood (7) found that in recumbent subjects whose urine volumes were relatively low during a control hour the ingestion of 1 liter of tap water led to an increased excretion of sodium whereas those whose control urine volumes were high excreted less sodium after water loading. Seldin and Tarail (8) noted only a slight initial increase in sodium excretion in two normal subjects who accumulated positive water balances of approximately 2.5 liters by drinking water at a rate of 20 to 22 $\mathrm{ml} . / \mathrm{min}$. Blomhert (9) made similar observations in subjects ingesting 2 liters of water over a period of one hour. We have observed slight transient increases in sodium excretion under similar circumstances (10). That these changes are not merely due to a "washing-out" effect involving the renal dead-space and delay time is indicated by the fact that the excretion of creatinine and other solutes undergoes no similar changes. In an endeavor further to elucidate this matter we have administered 10 units of posterior pituitary extract (Pitressin, Parke, Davis \& Co.) to two recumbent normal subjects after a control period of two hours, and then, two hours after the Pitressin injection, while its antidiuretic effect was still present, had the subjects ingest 3 liters of tap water. Sodium excretion averaged 198 micro-eq./ min. before Pitressin, 122 micro-eq./min. during the first two hours after Pitressin and 160 microeq./min. during the next two hours of hydration. Serum sodium averaged 139.3 meq./1. before hydration and 131.6 meq./1. after. Plasma volume, estimated from changes in hemoglobin, hematocrit and total serum protein, increased by 3.5 per cent, indicating that a significant quantity of the water had actually been absorbed from the gastro-intestinal tract. It would thus appear that expansion of total body water has a relatively minor effect on the excretion of sodium, at least when serum sodium concentration is lowered.

In an endeavor to ascertain the effect of expansion of the extracellular compartment, experiments were devised in which the volume of extracellular water was expanded at the same time that the concentrations of sodium and chloride therein were reduced. Under these conditions any renal or extra-renal effects ascribable to an increased concentration of these ions either in extracellular fluid or in glomerular filtrate could be eliminated from consideration.

\section{METHODS}

The subjects were essentially healthy male adults admitted for the study of minor complaints and free from significant physical abnormalities. They came to the 
laboratory one to two hours after a breakfast low in salt, were weighed, arterialized blood was withdrawn (11) without stasis from an antecubital vein, and $1,500 \mathrm{ml}$. of tap water was imbibed during a period of one-half to one hour. They stood up to void every half hour, following which they drank an amount of tap water slightly in excess of the urine volume so as to replace insensible loss and maintain the body weight $1.5 \mathrm{Kg}$. greater than the initial weight. ${ }^{2}$ After a satisfactory diuresis had been in progress for two hours blood for analysis was withdrawn and the intravenous infusion of 2 liters $^{3}$ of a solution containing $112 \mathrm{meq}$. of sodium, $90 \mathrm{meq}$. of chloride and 22 meq. of bicarbonate per liter was commenced at a rate of approximately $20 \mathrm{ml} . / \mathrm{min}$. The ingestion of water every half hour was continued so that at the conclusion of the infusion the body weight was maintained $3.5 \mathrm{Kg}$. above the initial weight. Blood was withdrawn at the conclusion of the infusion and two hours later. The study was terminated three or four hours after completion of the infusion. Although ideally it would have been preferable to have employed the same subjects for both the sitting and recumbency studies, this was not done because of the rather ardious nature of these experiments for the subjects.

Analytic methods and formulae for calculation of changes in plasma volume were identical to those described in a recent report from this laboratory (12).

\section{RESULTS}

The rates of urine flow and electrolyte excretion, sodium concentration and creatinine clearance, together with analyses made on venous blood and calculated changes in plasma volume are given in Table I. The rate of sodium excretion is shown graphically in Figure 1.

The absence of any significant change in calculated plasma volume together with the fall in concentration of electrolytes in extracellular water following the establishment and during the maintenance of a tap water load of $1,500 \mathrm{ml}$. is consistent with the belief that, as absorbed, this water is distributed throughout the entire volume

2 Without such preliminary and sustained water loading it is difficult to prevent a rise in serum electrolyte concentration following the infusion of hypotonic solutions since an initial effect of expanded extracellular volume appears to be that of inhibition of antidiuretic hormone secretion, leading to the excretion of urine which is more dilute than the infused solution and thus obligatorily raising the concentration of electrolytes in the serum $(9,12)$. Furthermore, such loading leads to continued large urine volumes, minimizing collection and timing errors as well as renal dead-space changes.

3 In the case of Subject A. L. whose weight was 110 Kg., 3 liters were infused.
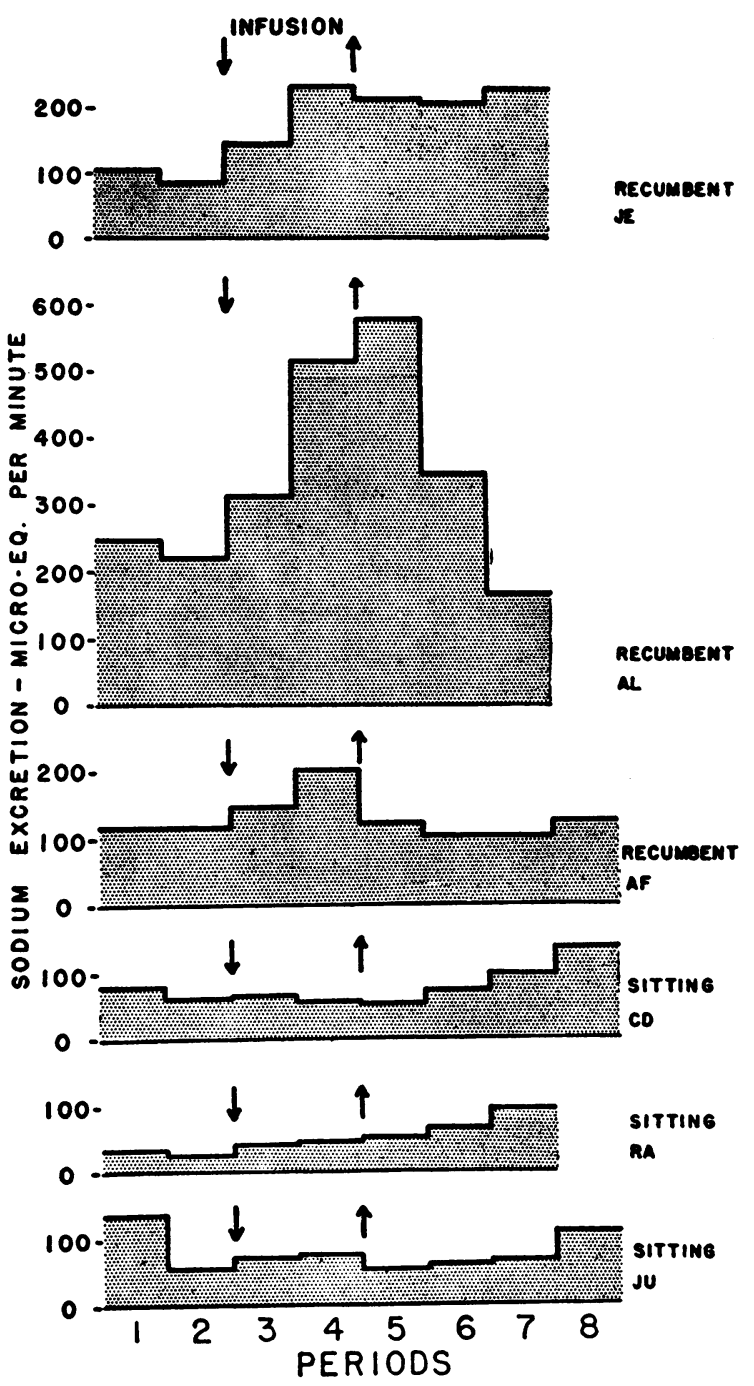

Fig. 1. The Effect of the Intravenous Infusion of Hypotonic Sodiuid Chloride and Bicarbonate Solution on Sodium Excretion in Water-LoAded SubJects

Note that subject A. L., whose weight was $110 \mathrm{Kg}$., received 3 liters; the others 2 liters.

of body water. Calculation of the extracellular volume from the chloride balance and chloride concentration in extracellular water before and after the infusion indicated increases of 12 to 16 per cent following the infusion of $2,000 \mathrm{ml}$. of hypotonic sodium chloride and bicarbonate solution (containing the amount of sodium normally present in 1,600 $\mathrm{ml}$. of extracellular fluid). Thus the calculated expansion of extracellular volume, also reflected in the calculated increases in plasma volume, agree with the anticipated changes. 


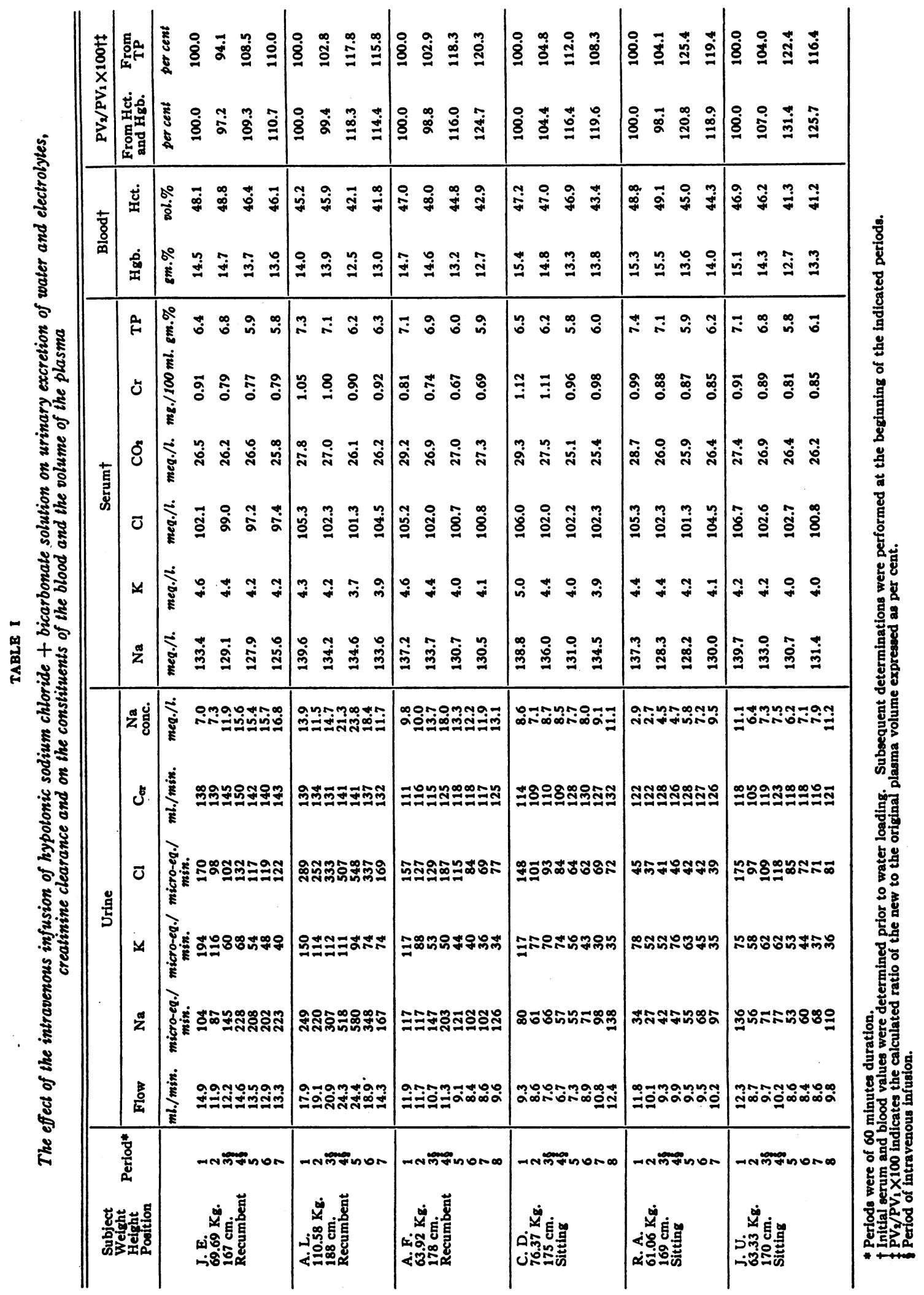


In each observation with the subject recumbent, sodium excretion rose during the infusion and remained elevated for several hours. This increased excretion of sodium was in every instance associated with a rise in its concentration in the urine as well as with an increased rate of urine flow. The dependence of urine flow upon electrolyte and particularly sodium excretion, during states when antidiuretic hormone activity may be presumed to be minimal or absent previously described by us (13), has been considered to conform with the view that the water available for facultative excretion is related to the distal load of sodium (14). It will be noted that in every instance the concentrations of sodium, chloride and bicarbonate in the extracellular water fell during the infusion of the hypotonic solution, while creatinine clearance remained unchanged. Thus the filtered load of sodium was actually decreased at the time during which the excretion rate was increasing.

The total sodium excretion during the first five hours after beginning the infusion averaged 13.4 per cent of the amount infused in the recumbent subjects and only 4.4 per cent in the seated subjects.

In contrast to the effects in recumbent subjects, little augmentation of sodium excretion above the pre-infusion rate occurred in the seated subjects, and that only several hours after the infusion was completed. However, this rise in excretion is to be contrasted with the decline which might have been anticipated without the infusion (10). Whether this late rise represents a simple temporal delay in the phenomena observed in the recumbent subjects is not apparent.

\section{DISCUSSION}

The augmented excretion of sodium uniformly observed with subjects in the recumbent position at a time when the serum electrolyte concentrations were reduced and creatinine clearances unchanged can only be explained by diminished tubular reabsorption of sodium. In view of the fact that the depression of serum electrolyte concentration was unaccompanied by any shift in ionic pattern one can hardly ascribe the increased sodium excretion to its obligation by chloride-an interpretation which might be placed on the increased sodium excretion which accompanies an infusion of isotonic saline (12), and which occurs in the sitting as well as recumbent positions.
It is conceivable that the lowering of the oncotic pressure of the plasma served as the stimulus for diminished reabsorption of sodium. However, a reduction of equal magnitude occurred in the experiments with the subjects sitting, in which sodium excretion was little or not at all augmented. A similar argument may be raised against the unlikely hypothesis that the decreased concentration of serum sodium, with the concomitant fall in electrolyte concentration within the tubule cells, serves as a stimulus for sodium rejection or that an increase in renal interstitial fluid as part of the general expansion of extracellular volume leads to diminished sodium reabsorption.

That the locus of action of expanded extracellular volume is in the cephalad portion of the body is suggested by the lesser increase in sodium excretion in the sitting position. The observation of Harrison and associates $(15,16)$, that in sitting subjects increasing intracranial pressure by means of an inflated blood pressure cuff about the neck produces an augmented sodium excretion, is consistent with this hypothesis. Evidence has already been presented (12) indicating that the secretion of antidiuretic hormone is responsive to volume changes within the cranium. It might well be that the anterior pituitary or some intracranial center which influences its activity is likewise sensitive to volume changes or some factor associated with them, and that the release of salt-retaining adrenal hormones is thus modified, as suggested by Peters and colleagues (17) who studied a saltwasting syndrome associated with cerebral disease. An hypothesis suggested is that "the excitation of the anterior pituitary gland as it relates to the secretion of adrenocorticotrophic hormone may be under a modifying influence from some nucleus or tract in the central nervous system. A lesion at such a site might disorganize an automatic sequence that normally leads to the secretion of ACTH and in turn of salt retaining hormone from the adrenal cortex" (17). An alternate hypothesis is that the central nervous system can directly modify the tubular reabsorption of salt.

The apparent converse of the above syndrome has also been reported. Hypernatremia and hyperchloremia associated with little or no salt excretion in the urine have been reported by Allott (18), Sweet and his coworkers (19), MacCarty and Cooper (20), and Higgins and associates (21) in 
patients with serious brain damage, all of whom eventually succumbed. Luetscher's and Blackman's (22) cases of hypernatremia in association with brain damage ascribed to sulfonamides, although similar to the above cases, were all complicated by concomitant renal damage. In all these cases of hypernatremia it might well be that the difficulty resided at least in part in the failure of the supra-optico-hypophyseal system to respond normally to hypertonicity, although clear-cut diabetes insipidus was not noted. Furthermore Lewy and Gassmann (23) have produced hyperchloremia and hypochloruria but not polyuria in cats by inducing lesions in the paraoptic nuclei.

Previous studies $(6,9,12)$ have demonstrated that expansion of extracellular volume (plasma and interstitial fluid) appears to diminish tubular reabsorption of water via decreased antidiuretic $(\mathrm{ADH})$ activity. The present observations suggest that expanded extracellular volume diminishes tubular reabsorption of sodium. If, as seems not unreasonable, the converse of these propositions holds, namely, that diminished extracellular volume (or some associated factor) in the cephalad portion of the body leads to 1 ) sodium retention through increased tubular reabsorption and 2) water retention in excess of sodium through increased $\mathrm{ADH}$ activity, one may be in a position to explain the occurrence of these phenomena in certain cases of decompensated hepatic cirrhosis with ascites. In this condition the obviously increased volume of fluid below the diaphragm is not infrequently associated with clinical evidence of dehydration of the head, neck, arms and upper chest. These patients characteristically retain sodium with avidity, but in addition frequently exhibit hyponatremia $(24,25)$ often accompanied by relatively scanty urine of high specific gravity suggestive of $\mathrm{ADH}$ activity which indeed has been demonstrated by Ralli and colleagues (26). With improvement in liver function, the serum sodium tends to rise and the hematocrit to fall, the latter suggesting that an expansion of plasma volume has occurred, since it is unlikely that clinical improvement would be accompanied by either diminished blood formation or increased blood destruction. Although the low serum sodium might be a reflection of intracellular electrolyte deficit as appears to be the case in tuberculosis (27), the fact that large quantities of water may be retained without salt following paracentesis (28) suggests increased $\mathrm{ADH}$ activity. The rising hematocrit and manifestations of circulatory insufficiency which may appear under these circumstances (28) are further indications of a shrinking plasma volume.

It is also of interest that in decompensated cirrhosis, the urine volume and sodium excretion are generally larger at night when the patients are more recumbent than in the daytime (29). This is of particular note since the normal subject has a smaller water and salt excretion at night than during the day-the mechanism of which has not as yet been satisfactorily explained.

It has been suggested that in the initial stages of heart failure a redistribution of blood to the central portions of the vascular bed will necessarily be attended by a deficit of blood and extravascular fluid in the periphery, and presumably in the cranial cavity (16). Although it seems unwise to speculate further, it may be noted that in congestive heart failure, as in cirrhosis, the excretion of water and sodium during nocturnal recumbency exceeds the rate which obtains by day (29). Even the patient in severe failure maintained at strict bed rest tends to assume a less vertical position during sleep than when complying with the postural demands of orthopnea during the day.

\section{CONCLUSIONS}

1. Hypotonic expansion of the extracellular fluid volume in the recumbent, water-loaded subject leads to an increased urinary excretion of sodium although the filtered load presented to the renal tubules is actually diminished.

2. The failure of a similar expansion of extracellular volume significantly to augment sodium excretion in the seated subject suggests that the locus of action of expanded volume (or some associated factor) is in the cephalad portion of the body.

3. The hypothesis is suggested that the converse of these observations also holds-contraction of extracellular volume (or an associated factor) in the cephalad portion of the body may be a stimulus for sodium retention.

\section{ACKNOWLEDGMENT}

The technical assistance of Miss Miriam E. Halpin and Mrs. Eleanor G. Harkins is gratefully acknowledged. 


\section{REFERENCES}

1. Starling, E. H., and Verney, E. B., The secretion of urine as studied on the isolated kidney. Proc. Roy. Soc. London, Series B., 1925, 97, 321.

2. Eggleton, M. G., Pappenheimer, J. R., and Winton, F. R., The mechanisms of dilution diuresis in the isolated kidney and the anesthetized dog. J. Physiol., 1940, 98, 336.

3. Wesson, L. G., Jr., Anslow, W. P., Jr., Raisz, L. G., Bolomey, A. A., and Ladd, M., Effect of sustained expansion of extracellular fluid volume upon filtration rate, renal plasma flow and electrolyte and water excretion in the dog. Am. J. Physiol., 1950, 162, 677.

4. McCance, R. A., Young, W. F., and Black, D. A. K., The secretion of urine during dehydration and rehydration. J. Physiol., 1944, 102, 415.

5. Peters, J. P., Sodium, water and edema. J. Mt. Sinai Hosp., 1950-51, 17, 159.

6. Welt, L. G., and Orloff, J., The effects of an increase in plasma volume on the metabolism and excretion of water by normal subjects. J. Clin. Invest., 1951, 30, 751.

7. Crutchfield, A. J., Jr., and Wood, J. E., Jr., Urine volume and total renal sodium excretion during water diuresis. Ann. Int. Med., 1948, 28, 28.

8. Seldin, D. 'W., and Tarail, R., Effect of hypertonic solutions on metabolism and excretion of electrolytes. Am. J. Physiol., 1949, 159, 160.

9. Blomhert, G., Over de Zogenaamde Waterdiurese. Scheltema \& Holkema, Amsterdam, 1951.

10. Rosenbaum, J. D., Nelson, W. P., III, Davis, R. K., and Strauss, M. B. Unpublished observations.

11. Meakins, J. C., and Davies, H. W., Observations on the gases in human arterial and venous blood. $\mathrm{J}$. Path. \& Bacteriol., 1920, 23, 451.

12. Strauss, M. B., Davis, R. K., Rosenbaum, J. D., and Rossmeisl, E. C., "Water diuresis" produced during recumbency by the intravenous infusion of isotonic saline solution. J. Clin. Invest., 1951, 30, 862.

13. Rosenbaum, J. D., Nelson, W. P., III, and Strauss, M. B., The dependence of water diuresis upon electrolyte excretion. J. Clin. Invest., 1950, 29, 841.

14. Smith, H. W., The Kidney. Structure and Function in Health and Disease. Oxford University Press, New York, 1951.

15. Lewis, J. M., Jr., Buie, R. M., Sevier, S. M., and Harrison, T. R., The effect of posture and of congestion of the head on sodium excretion in normal subjects. Circulation, 1950, 2, 822.
16. Viar, W. N., Oliver, B. B., Eisenberg, S., Lombardo, T. A., Willis, K., and Harrison, T. R., The effect of posture and of compression of the neck on excretion of electrolytes and glomerular filtration: further studies. Circulation, 1951, 3, 105.

17. Peters, J. P., Welt, L. G., Sims, E. A. H., Orloff, J., and Needham, J., A salt-wasting syndrome associated with cerebral disease. Tr. A. Am. Physicians, 1950, 53, 57.

18. Allott, E. N., Sodium and chlorine retention without renal disease. Lancet, 1939, 1, 1035.

19. Sweet, W. H., Cotzias, G. C., Seed, J., and Yakovlev, P. I., Gastro-intestinal hemorrhages, hyperglycemia, azotemia, hyperchloremia and hypernatremia following lesions of the frontal lobe in man. A. Research Nerv. \& Ment. Dis., Proc., 1948, 27, 795.

20. MacCarty, C. S., and Cooper, I. S., Neurologic and metabolic effects of bilateral ligation of the anterior cerebral arteries in man. Proc. Staff Meetings Mayo Clinic, 1951, 26, 185.

21. Higgins, G., Lewin, W., O'Brien, J. R. P., and Taylor, W. H., Metabolic disorders in head injury. Hyperchloraemia and hyperchloruria. Lancet, 1951, 1, 1295.

22. Luetscher, J. A., Jr., and Blackman, S. S., Jr., Severe injury to kidneys and brain following sulfathiazole administration: high serum sodium and chloride levels and persistent cerebral damage. Ann. Int. Med., 1943, 18, 741.

23. Lewy, F. H., and Gassmann, F. K., Experiments on the hypothalamic nuclei in the regulation of chloride and sugar metabolism. Am. J. Physiol., 1935, $112,504$.

24. Combined Staff Clinic (College of Physicians and Surgeons, Columbia University), Mechanisms of ascites formation. Am. J. Med., 1950, 9, 102.

25. Eisenmenger, W. J., Blondheim, S. H., Bongiovanni, A. M., and Kunkel, H. G., Electrolyte studies on patients with cirrhosis of the liver. J. Clin. Invest., 1950, 29, 1491.

26. Ralli, E. P., Robson, J. S., Clarke, D., and Hoagland, C. L., Factors influencing ascites in patients with cirrhosis of the liver. J. Clin. Invest., 1945, 24, 316.

27. Sims, E. A. H., Welt, L. G., Orloff, J., and Needham, J. W., Asymptomatic hyponatremia in pulmonary tuberculosis. J. Clin. Invest., 1950, 29, 1545.

28. Nelson, W. P., III., Rosenbaum, J. D., and Strauss, M. B., Hyponatremia in hepatic cirrhosis following paracentesis. J. Clin. Invest., 1951, 30, 738.

29. Borst, J. G. G., and de Vries, L. A., The three types of "natural" diuresis. Lancet, 1950, 2, 1. 